\section{Magnetic Resonance Imaging Property of Doxorubicin-Loaded Gadolinium/13X Zeolite/Folic Acid Nanocomposite}

\author{
Ghaderi S.,2®, Divband B.3,4, Gharehaghaji N. ${ }^{5 * \odot}$
}

\begin{abstract}
Background: Magnetic resonance imaging (MRI) using nanostructures has been a proper method for tumor targeting purposes. Different MRI nanomaterials, targeting agents and anticancer drugs have been used for targeting of tumors.

Objectives: This study aims to consider the MRI property of doxorubicin (DOX)-loaded gadolinium/13X zeolite/folic acid $\left(\mathrm{Gd}^{3+} / 13 \mathrm{X} / \mathrm{FA}\right)$ nanocomposite.

Material and Methods: In this in vitro study, $\mathrm{Gd}^{3+} / 13 \mathrm{X} / \mathrm{FA} / \mathrm{DOX}$ nanocomposite was prepared and the X-ray diffraction, scanning electron microscopy and MTT assay were conducted to evaluate the physicochemical properties of the nanocomposite. MRI was performed at $25^{\circ} \mathrm{C}$ using a $1.5 \mathrm{~T}$ clinical system to determine the $\mathrm{T} 1$ relaxation times and subsequently, the $\mathrm{T} 1$ relaxivity.

Results: The size of the nanocomposite was in the range of 80-200 nm. The nanocomposite without DOX loading $\left(\mathrm{Gd}^{3+} / 13 \mathrm{X} / \mathrm{FA}\right)$ showed compatibility for A549 cells for all concentrations while DOX-loaded nanocomposite was toxic for $62 \%$ of the cells at the concentration of $0.4 \mathrm{mg} / \mathrm{ml}$. The $\mathrm{T} 1$ relaxivity of $\mathrm{Gd}^{3+} / 13 \mathrm{X} / \mathrm{FA} / \mathrm{DOX}$ nanocomposite was $4.0401 \mathrm{mM}^{-1} \mathrm{~s}^{-1}$.
\end{abstract}

Conclusion: $\mathrm{Gd}^{3+} / 13 \mathrm{X} / \mathrm{FA} / \mathrm{DOX}$ nanocomposite shows a $\mathrm{T} 1$ relaxivity similar to the conventional gadolinium chelates, and a successful DOX loading.

Citation: Ghaderi S, Divband B, Gharehaghaji N. Magnetic Resonance Imaging Property of Doxorubicin-Loaded Gadolinium/13X Zeolite/ Folic Acid Nanocomposite. J Biomed Phys Eng. 2020;10(1):103-110. doi: 10.31661/jbpe.v0i0.1254.

\section{Keywords}

Magnetic Resonance Imaging; Relaxivity; Gadolinium; Doxorubicin; Folic Acid; 13X zeolite

\section{Introduction}

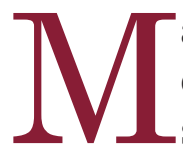

agnetic resonance imaging (MRI) using nanostructures is an efficient method used for different biomedical applications such as cancer imaging [1], inflammation detection [2] and perfusion imaging [3]. MRI-guided targeted drug delivery represents another significant application of MRI, which has been important, recently [4]. A favorable procedure, which is useful for detection and treatment of cancers, includes combination of diagnostic and therapeutic features. The imaging methods are to detect tumor areas by improving the signal between the neoplasm and healthy tissues surrounding while the theraputic agents are released in the tumor site [5]. Magnetic nanoparticles are appropriate to be used in these procedures because of their ability to improve contrast in MRI as a medical diagnostic tool for therapeutic
${ }^{1} \mathrm{MSc}$, Medical Radia-

tion Sciences Research

Team, Tabriz University

of Medical Sciences,

Tabriz, Iran

${ }^{2} \mathrm{MSc}$, Department of

Radiology, Faculty of

Paramedicine, Tabriz

University of Medical Sci-

ences, Tabriz, Iran

${ }^{3} \mathrm{PhD}$, Dental and

Periodontal Research

Center, Tabriz University

of Medical Sciences,

Tabriz, Iran

${ }^{4} \mathrm{PhD}$, Inorganic Chemis-

try Department, Faculty

of Chemistry, University

of Tabriz, Tabriz, Iran

${ }^{5} \mathrm{PhD}$, Department of

Radiology, Faculty of

Paramedicine, Tabriz

University of Medical Sci-

ences, Tabriz, Iran

*Corresponding author:

N. Gharehaghaji

Department of Radiol-

ogy, Faculty of Paramedi-

cine, Tabriz University

of Medical Sciences,

University Street, Tabriz,

Iran

E-mail: gharehaghajin@

tbzmed.ac.ir

Received: 16 September 2019

Accepted: 2 October 2019 
purposes such as hyperthermia and targeted drug delivery [6].

Among various contrast agents of MRI, gadolinium $\left(\mathrm{Gd}^{3+}\right)$-based materials have an optimal structure to produce positive signal in MRI due to a significant effect on the reduction of $\mathrm{T} 1$ relaxation time. They have been widely used in clinical MRI as chelate forms. However, gadolinium chelates have some disadvantages, including low detection sensitivity, toxicity attention and short blood circulation time [7]. On the other hand, $\mathrm{Gd}^{3+}$ nanoparticles have been used more recently due to their low toxicity, good solubility, excellent physicochemical properties and high relaxivity [8]. Recent advances in molecular imaging have produced an additional requirement for the use of targeted contrast materials and an increase in their sensitivity [9].

Folic acid (FA) is a vitamin with low molecular weight, which is used as a tumor-targeting agent for various types of tumor cells [10]. Because of high binding affinity of folate receptor for folic acid, FA can move into the cancer cells via receptor-mediated endocytosis $[11,12]$. Therefore, anticancer drug can be imported to the cells. FA has also other advantages such as non-immunogenic property, stability and low cost [11].

Doxorubicin (DOX) is an anticancer drug, which has been widely used for treatment of different types of cancer. Direct intravascular injection of DOX in chemotherapy patients has severe toxicity to normal cells and shows the side effects due to the low specificity of DOX to cancer cells [13]. The problem is solved by systems of tumor-targeted drug delivery [14]. One of these systems was DOX-loaded Gd-FA-Si nanoplatform, which was developed by Zhang et al. The nanosystem also showed capability as a T1 contrast agent for MRI [15]. In another study with $\mathrm{ZnO} @ \mathrm{Gd}_{2} \mathrm{O}_{3}$ nanoparticles, attachment of DOX and FA to the surface of the nanoparticles was performed through amino groups. The resultant multimodal nanostructures were re- ported as good T2 contrast agents for MRI [12].

Zeolites are microporous crystalline aluminosilicate materials, which have the unique chemical structure, and consist of channels and holes [16]. They can act as a substitute for guest molecules like gadolinium ions [17]. Thus, different studies have been carried out using various types of zeolites in MRI. In one study, the chemical stability of $\mathrm{Gd}^{3+}$-loaded $\mathrm{NaY}$ zeolite was investigated at low $\mathrm{pH}$ and in the presence of some cations with the concentrations similar to gastrointestinal tract. Besides, the effect of $\mathrm{Gd}^{3+}$ loading on the relaxivity was studied [18]. In another study, $\mathrm{Gd}^{3+}$-loaded $\mathrm{NaY}$ or $\mathrm{NaA}$ zeolites were introduced as potential MRI contrast agents in the high field; in addition, the relationship between the structure of the zeolites and the relaxivities was investigated [19].

Although the different $\mathrm{Gd}^{3+}$-loaded zeolites have been investigated for MRI; in addition, DOX and FA have been used in the structure of the various targeted agents, to our knowledge, the MRI property of $\mathrm{Gd}^{3+} / 13 \mathrm{X} / \mathrm{FA} / \mathrm{DOX}$ nanocomposite has not been investigated. This study aims to consider $\mathrm{Gd}^{3+} / 13 \mathrm{X} / \mathrm{FA} / \mathrm{DOX}$ nanocomposite potential as an MRI contrast agent with the ability of DOX loading.

\section{Material and Methods}

\section{Preparation of $\mathrm{Gd}^{3+} / 13 \mathrm{X} / \mathrm{FA} / \mathrm{DOX}$ nanocomposite}

In this in vitro study, the $13 \mathrm{X}$ zeolite was prepared based on the study carried out by Mesgari-Shadi et al [20]. It was dispersed in 2 $\mathrm{ml}$ distilled water using an ultrasound device for $2 \mathrm{~h}$. Then, gadolinium chloride solution with a ratio of $2.6 \mathrm{wt} \%$ zeolite was added to the suspension, stirred at room temperature for $24 \mathrm{~h}$ with a magnetic stirrer and centrifuged. FA was added to the suspension containing $5 \mathrm{~g}$ of the zeolite in $10 \mathrm{ml}$ of distilled water. Then prepared $\mathrm{Gd}^{3+} / 13 \mathrm{X} / \mathrm{FA}$ nanocomposite was dispersed in $5 \mathrm{ml}$ of doxorubicin solution, 
stirred for $12 \mathrm{~h}$ at $25^{\circ} \mathrm{C}$, centrifuged and dried under vacuum for $24 \mathrm{~h}$. The final product was $\mathrm{Gd}^{3+} / 13 \mathrm{X} / \mathrm{FA} / \mathrm{DOX}$.

\section{Characterization}

Several characterization tools were employed to identify the physicochemical properties of $\mathrm{Gd}^{3+} / 13 \mathrm{X} / \mathrm{FA} / \mathrm{DOX}$ nanocomposite. To collect X-ray diffraction patterns (XRD) at room temperature and record scanning electron microscope (SEM) images, a Philips diffractometer and a Philips ES $30 \mathrm{~kW}$ device were used, respectively. MR imaging of the samples was carried out at $25{ }^{\circ} \mathrm{C}$ using a 1.5 $\mathrm{T}$ horizontal bore MRI system (Magnetom Avanto, Siemens Healthcare, Erlangen, Germany).

\section{In vitro MTT assay}

MTT (3-(4, 5-dimethylthiazol-2-yl)-2-5-diphenyltetrazolium bromide) assay is one of the routine methods to evaluate cytotoxicity or cell viability. In this study, A549 alveolar adenocarcinoma cells were incubated in 96-well plates $\left(8 \times 10^{3}\right.$ cells for each well). Then, the cells were cultured at $5 \% \mathrm{CO}_{2}$ and $37{ }^{\circ} \mathrm{C}$. Different concentrations, including $0.05,0.1,0.2$ and $0.4 \mathrm{mg} / \mathrm{ml}$ of $\mathrm{Gd}^{3+} / 13 \mathrm{X} / \mathrm{FA}$ or $\mathrm{Gd}^{3+} / 13 \mathrm{X} /$ FA/DOX nanocomposites were added to the culture media and the A549 cells were incubated for $24 \mathrm{~h}$. Next steps were carried out as follow:

- Adding $50 \mu \mathrm{L}$ of $2 \mathrm{mg} / \mathrm{ml}$ MTT solution and $150 \mu \mathrm{L}$ culture medium to each well and incubating for $4 \mathrm{~h}$ at $37^{\circ} \mathrm{C}$ and $5 \% \mathrm{CO}_{2}$.

- Washing wells with Phosphate-buffered solution and removing the residual media.

- Adding dimethyl sulfoxide and Sorenson buffer as solubilizer to each well.

- Measuring the absorbance at $570 \mathrm{~nm}$ using an ELISA plate reader (BioTeck, Bad Friedrichshall, Germany).

MRI and relaxivity measurement

Different concentrations of $\mathrm{Gd}^{3+} / 13 \mathrm{X} / \mathrm{FA} /$ DOX nanocomposite were prepared in the glass tubes and dispersed by ultrasound device (SOLTEC, Italy) for 30 minutes. Addition of $10 \mathrm{ml}$ agar to the nanocomposite samples was carried out to prevent from precipitation and aggregation of the samples. For the MRI study, the glass tubes were placed in a watercontaining plastic phantom, which was adjusted in the center of a quadrature head coil.

The T1 weighted images were prepared using a spin echo pulse sequence with different TRs (250, 450, 1000, 1800 and $2500 \mathrm{~ms})$ and a constant TE of $11 \mathrm{~ms}$, a matrix size of $384 \times$ 384 , a field of view (FOV) of $189 \times 189 \mathrm{~mm}^{2}$ and a slice thickness (ST) of $3 \mathrm{~mm}$. The signal intensity values of the samples were measured using DicomWorks software. Plotting the curves of the $\mathrm{T} 1$ relaxation time and subsequently calculating of the $1 / \mathrm{T} 1$ relaxation rates were carried out using MATLAB software (r2018b). The 1/T1 values were used to plot the T1 relaxivity graph, which showed the relationship between the amounts of 1/T1 and the different $\mathrm{Gd}^{3+}$ concentrations of $\mathrm{Gd}^{3+} / 13 \mathrm{X} /$ FA/DOX nanocomposite.

\section{Results}

Preparation and characterization of the nanocomposite

Figure 1 shows the schematic illustration of the prepared $\mathrm{Gd}^{3+} / 13 \mathrm{X} / \mathrm{FA} / \mathrm{DOX}$ nanocomposite.

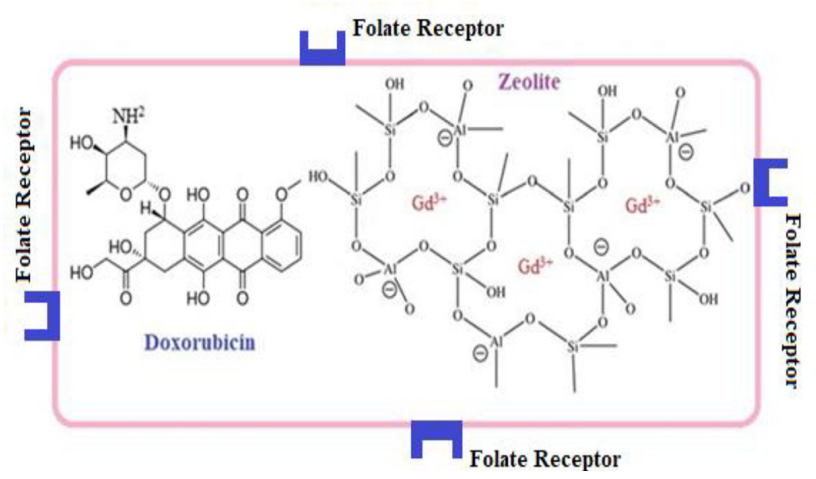

Figure 1: Schematic illustration of $\mathrm{Gd}^{3+} / 13 \mathrm{X} /$ FA/DOX nanocomposite. 
Ghaderi S., Divband B., Gharehaghaji N.

XRD spectrum showed the peaks related to the $13 \mathrm{X}$ zeolite (Figure 2a). According to Fig- ure $2 b$, the size of the nanocomposite was in the range of 80-200 $\mathrm{nm}$.

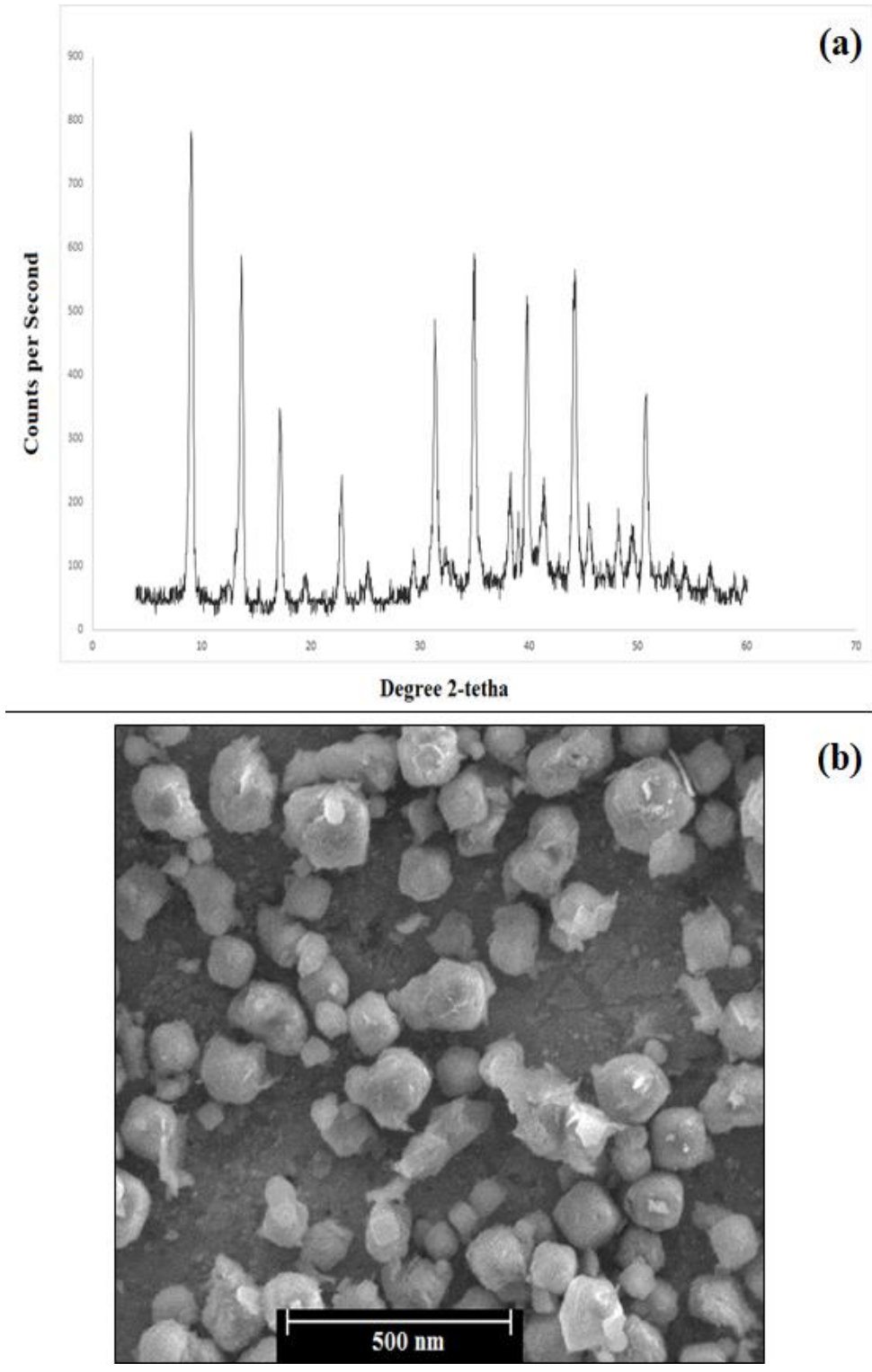

Figure 2: a) XRD spectrum and b) SEM image of $\mathrm{Gd}^{3+} / 13 \mathrm{X} / \mathrm{FA} / \mathrm{DOX}$ nanocomposite.

In vitro MTT assay

Figure 3 illustrates the MTT assay results for A549 cells following $24 \mathrm{~h}$ incubation with various concentrations of $\mathrm{Gd}^{3+} / 13 \mathrm{X} / \mathrm{FA}$ and $\mathrm{Gd}^{3+} / 13 \mathrm{X} / \mathrm{FA} / \mathrm{DOX}$ nanocomposites. The relative cell viability of $\mathrm{Gd}^{3+} / 13 \mathrm{X} / \mathrm{FA} / \mathrm{DOX}$ was lower than $\mathrm{Gd}^{3+} / 13 \mathrm{X} / \mathrm{FA}$ nanocomposite for all concentrations. $\mathrm{Gd}^{3+} / 13 \mathrm{X} / \mathrm{FA}$ showed the cell viability greater than $80 \%$ even for the concentration of $0.4 \mathrm{mg} / \mathrm{ml}$ as the highest concentration. On the other hand, for $\mathrm{Gd}^{3+} / 13 \mathrm{X} /$ FA/DOX, the relative cell viability was less than $80 \%$ for all samples so that the cell killing at the concentration of $0.4 \mathrm{mg} / \mathrm{ml}$ was higher than $60 \%$. 


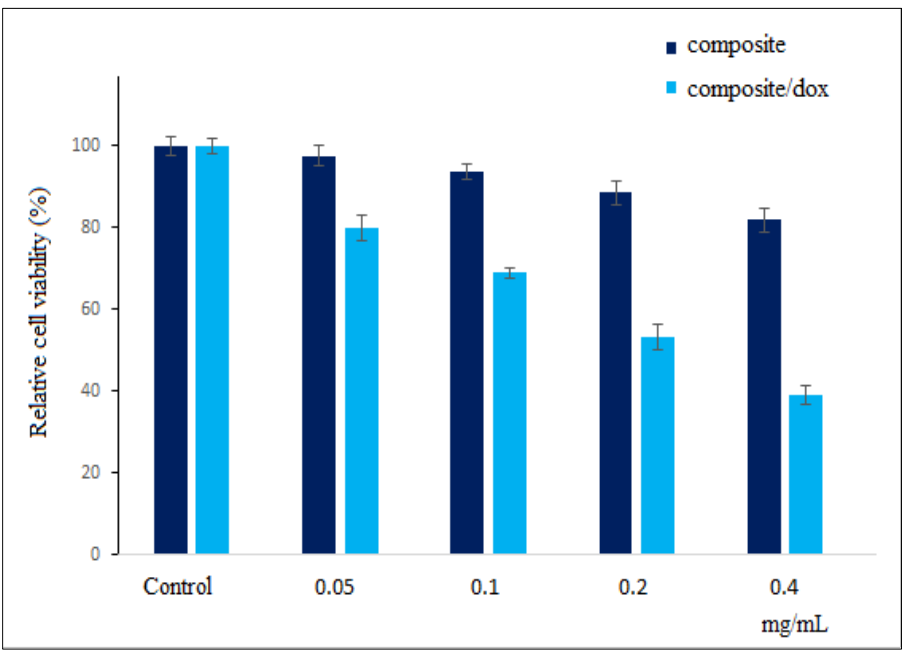

Figure 3: Relative A549 cell viability following $24 \mathrm{~h}$ incubation with various concentrations of $\mathrm{Gd}^{3+} / 13 \mathrm{X} / \mathrm{FA}$ and $\mathrm{Gd}^{3+} / 13 \mathrm{X} / \mathrm{FA} / \mathrm{DOX}$ nanocomposites.

\section{MRI Study}

Figure 4a shows a sample of the T1 weighted image of $\mathrm{Gd}^{3+} / 13 \mathrm{X} / \mathrm{FA} / \mathrm{DOX}$ nanocomposite with various $\mathrm{Gd}^{3+}$ concentrations, which was prepared with $\mathrm{TR}=450 \mathrm{~ms}$ and $\mathrm{TE}=11$ ms. Increasing of the samples' brightness as a function of $\mathrm{Gd}^{3+}$ concentration is seen in the figure. Moreover, increasing of TR was led to the incremental signal intensity at the same concentrations.
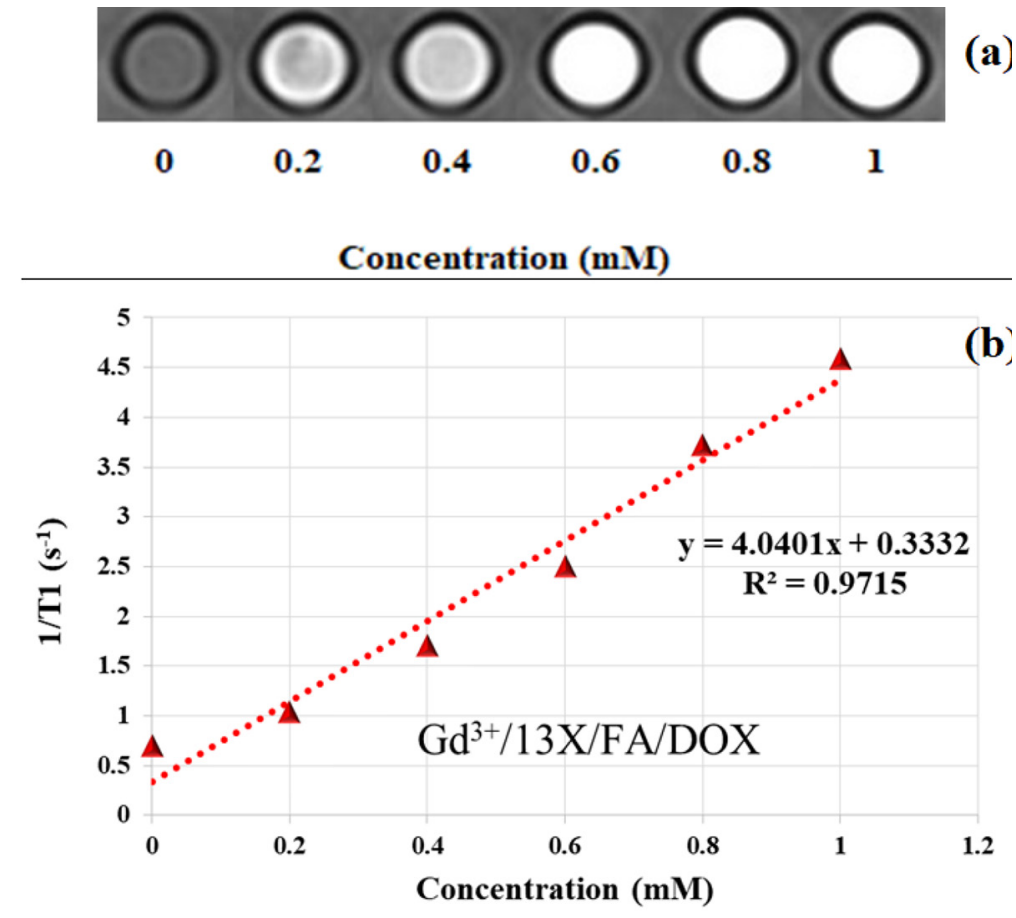

Figure 4: a) T1 weighted image of the various $\mathrm{Gd}^{3+}$ concentrations of $\mathrm{Gd}^{3+} / 13 \mathrm{X} / \mathrm{FA} / \mathrm{DOX}$ nanocomposite, b) T1 relaxivity graph of the nanocomposite 
According to Figure $4 \mathrm{~b}$, which shows the T1 relaxivity graph, the linear relationship between 1/T1 relaxation rates with $\mathrm{Gd}^{3+} / 13 \mathrm{X} /$ FA/DOX nanocomposite concentrations is seen. The T1 relaxivity of $\mathrm{Gd}^{3+} / 13 \mathrm{X} / \mathrm{FA} / \mathrm{DOX}$ was calculated $4.0401 \mathrm{mM}^{-1} \mathrm{~s}^{-1}$.

\section{Discussion}

Characterization and in vitro MTT assay

In XRD spectrum, the peaks of $13 \mathrm{X}$ zeolite were seen; however, $\mathrm{Gd}^{3+}$ did not show any peaks because of its ionic form resulted from ion exchange synthesis method.

According to the MTT assay results (Figure 3), $\mathrm{Gd}^{3+} / 13 \mathrm{X} / \mathrm{FA}$ indicated high compatibility with the cells for all concentrations while $\mathrm{Gd}^{3+} / 13 \mathrm{X} / \mathrm{FA} / \mathrm{DOX}$ showed cell-killing effect for all concentrations. This finding indicates the high ability of $\mathrm{Gd}^{3+} / 13 \mathrm{X} / \mathrm{FA} / \mathrm{DOX}$ to kill A549 alveolar adenocarcinoma cells confirming the successful loading of DOX to $\mathrm{Gd}^{3+} / 13 \mathrm{X} / \mathrm{FA}$ nanocomposite.

\section{MRI}

As seen in Figure 4a, increasing the concentration of $\mathrm{Gd}^{3+} / 13 \mathrm{X} / \mathrm{FA} / \mathrm{DOX}$ nanocomposite results in a more pronounced effect on the $\mathrm{T} 1$ relaxation time shortening. $\mathrm{Gd}^{3+}$ is a paramagnetic ion, which can affect both $\mathrm{T} 1$ and $\mathrm{T} 2$ relaxation times. In the low concentrations of gadolinium ions, the T1 shortening effect is dominant leading to the signal intensity increasing, and consequently, the positive contrast enhancement of the T1 weighted MR images. The TR amount controls the T1 weighting of the image. Therefore, difference for TR has a major effect on the image contrast.

T1 relaxivity shows the relationship between 1/T1 relaxation rate and $\mathrm{Gd}^{3+}$ concentrations. Based on Figure $4 b$, this relationship is linear for $\mathrm{Gd}^{3+} / 13 \mathrm{X} / \mathrm{FA} / \mathrm{DOX}$ nanocomposite. The linear dependence of 1/T1 to gadolinium ion concentration is necessary for each MRI contrast agent. The relaxivity of the nanocomposite is affected by the quantity of the gadolinium ions and the number of the available water protons for the $\mathrm{Gd}^{3+}$ magnetic centers. $13 \mathrm{X}$ zeolite is an $\mathrm{X}$ type zeolite with a high capacity for ion exchange, and $\mathrm{Si} / \mathrm{Al}$ ratio of 1-1.5 [21]. Due to the low ratio of $\mathrm{Si}$ to $\mathrm{Al}$, it shows hydrophilic property. The gadolinium ions as magnetic centers are encapsulated in the supercages, pores and channels of the zeolite. Because of the large size of the supercage cavity, the number of the $\mathrm{Gd}^{3+}$ in the supercages is higher than those of the pores and channels. Therefore, it is expected that the gadolinium ions have the highest access to the water protons through the supercages, and enough access via the pores and channels of the zeolite. In $\mathrm{Gd}^{3+} / 13 \mathrm{X} / \mathrm{FA} / \mathrm{DOX}$ nanocomposite, FA as targeted agent and DOX as anticancer agent are present. Since FA can bind to the $\mathrm{OH}$ groups of the zeolite, it occupies some of the pores and channels. Thus, the access of the gadolinium ions to the water protons via the pores and channels is limited. Although DOX cannot occupy the pores and channels of the zeolite due to the large size, it can be placed in the mouth of the pores and channels, and prevent from the access of the $\mathrm{Gd}^{3+}$ to the bulk water. Both of these situations lead to the lowering of the $\mathrm{T} 1$ relaxivity for $\mathrm{Gd}^{3+} / 13 \mathrm{X} /$ FA/DOX nanocomposite.

Although presence of FA and DOX reduces the $\mathrm{T} 1$ relaxivity value of $\mathrm{Gd}^{3+} / 13 \mathrm{X} / \mathrm{FA} / \mathrm{DOX}$ nanocomposite, its relaxivity is similar to the conventional gadolinium chelates. Additionally, the nanocomposite shows good ability for DOX loading. Comparing to other targeted porous nanocomposites, the $\mathrm{T} 1$ relaxivity of $\mathrm{Gd}^{3+} / 13 \mathrm{X} / \mathrm{FA} / \mathrm{DOX}$ is slightly lower than GdFA-Si nanoplatform [15]. It should be noted that the magnetic field strength was different in the studies.

\section{Conclusion}

In the present study, $\mathrm{Gd}^{3+} / 13 \mathrm{X} / \mathrm{FA} / \mathrm{DOX}$ nanocomposite was successfully prepared, 
MRI Property of DOX-loaded $\mathrm{Gd}^{3+} / 13 \mathrm{X} / \mathrm{FA}$ Nanocomposite

and the MRI property of the nanocomposite was investigated. The in vitro MTT assay results confirmed the cytocompatibility of the $\mathrm{Gd}^{3+} / 13 \mathrm{X} / \mathrm{FA}$ nanocomposite and the appropriate cell-killing effect of $\mathrm{Gd}^{3+} / 13 \mathrm{X} /$ FA/DOX, showing the successful loading of DOX. The MRI study revealed the capability of the nanocomposite to produce positive contrast in the $\mathrm{T} 1$ weighted images. $\mathrm{Gd}^{3+} / 13 \mathrm{X} /$ FA/DOX nanocomposite shows potential for using as $\mathrm{T} 1$ contrast material with successful loading of the anticancer drug. The investigation of the nanocomposite potential for tumor targeting in animal model can be done as a future work.

\section{Acknowledgment}

This work was adapted from the MSc thesis and supported by Medical Radiation Sciences Research Team, Tabriz University of Medical Sciences (Grant No: 1397.317).

\section{Conflict of Interest}

None

\section{References}

1. Oghabian MA, Guiti M, Haddad P, Gharehaghaji N, Saber R, Alam NR, et al. Detection sensitivity of MRI using ultra-small super paramagnetic iron oxide nano-particles (USPIO) in biological tissues. Conf Proc IEEE Eng Med Biol Soc. 2006:5625-6. doi: 10.1109/IEMBS.2006.260131. PubMed PMID: 17945909.

2. Lutz AM, Weishaupt D, Persohn E, Goepfert K, Froehlich J, Sasse B, et al. Imaging of macrophages in soft-tissue infection in rats: relationship between ultrasmall superparamagnetic iron oxide dose and MR signal characteristics. Radiology. 2005;234(3):765-75. doi: 10.1148/radiol.2343031172. PubMed PMID: 15665219.

3. Saharkhiz H, Gharehaghaji N, Nazarpoor M, Mesbahi A, Pourissa M. The Effect of Inversion Time on the Relationship Between Iron Oxide Nanoparticles Concentration and Signal Intensity in T1-Weighted MR Images. Iran J Radiol. 2014;11(2):e12667. doi: 10.5812/iranjradiol.12667. PubMed PMID: 25035696. PubMed PMCID: PMC4090637.

4. Ren L, Chen S, Li H, Zhang Z, Zhong J, Liu M, et al. MRI-guided liposomes for targeted tandem chemotherapy and therapeutic response prediction.
Acta Biomater. 2016;35:260-8. doi: 10.1016/j.actbio.2016.02.011. PubMed PMID: 26873364.

5. Ma Z, Wan H, Wang W, Zhang X, Uno T, Yang $Q$, et al. A theranostic agent for cancer therapy and imaging in the second near-infrared window. Nano Research. 2019;12(2):273-9. doi: 10.1007/ s12274-018-2210-x. PubMed PMID: 31832124. PubMed PMCID: PMC6907162.

6. Inozemtseva OA, German SV, Navolokin NA, Bucharskaya AB, Maslyakova GN, Gorin DA. Encapsulated magnetite nanoparticles: preparation and application as multifunctional tool for drug delivery systems. Nanotechnology and Biosensors. 2018;175-192. doi: 10.1016/B978-0-12-8138557.00006-4.

7. Stephen ZR, Kievit FM, Zhang M. Magnetite nanoparticles for medical MR imaging. Mater Today (Kidlington). 2011;14:330-8. doi: 10.1016/S13697021(11)70163-8. PubMed PMID: 22389583. PubMed PMCID: PMC3290401

8. Yang CT, Padmanabhan P, Gulyás BZ. Gadolinium (iii) based nanoparticles for $\mathrm{T}$ 1-weighted magnetic resonance imaging probes. RSC Advances. 2016;6(65):60945-66. doi: 10.1039/C6RA07782J.

9. Lin YS, Hung Y, Su JK, Lee R, Chang C, Lin ML, et al. Gadolinium (III)-incorporated nanosized mesoporous silica as potential magnetic resonance imaging contrast agents. The Journal of Physical Chemistry B. 2004;108(40):15608-11. doi: 10.1021/jp047829a.

10. Sun C, Sze R, Zhang M. Folic acid-PEG conjugated superparamagnetic nanoparticles for targeted cellular uptake and detection by MRI. J Biomed Mater Res A. 2006;78(3):550-7. doi: 10.1002/ jbm.a.30781. PubMed PMID: 16736484.

11. Stella B, Arpicco S, Peracchia MT, Desmaële $\mathrm{D}$, Hoebeke J, Renoir M, et al. Design of folic acid-conjugated nanoparticles for drug targeting. J Pharm Sci. 2000;89(11):1452-64. dio: 10.1002/1520-6017(200011)89:11<1452::aidjps8>3.0.co;2-p. PubMed PMID: 11015690.

12. Babayevska N, Florczak $P$, Woźniak-Budych $M$, Jarek M, Nowaczyk G, Zalewski T, et al. Functionalized multimodal Zn0@Gd203 nanosystems to use as perspective contrast agent for MRI. Applied Surface Science. 2017;404:129-37. doi: 10.1016/j. apsusc.2017.01.274.

13. Shen X, Li T, Chen Z, Geng Y, Xie X, Li S, et al. Luminescent/magnetic PLGA-based hybrid nanocomposites: a smart nanocarrier system for targeted codelivery and dual-modality imaging in cancer theranostics. Int J Nanomedicine. 2017;12:4299. doi: 10.2147/IJN.S136766. PubMed PMID: 
Ghaderi S., Divband B., Gharehaghaji N.

28652734. PubMed PMCID: PMC5473604.

14. Fernández M, Javaid F, Chudasama V. Advances in targeting the folate receptor in the treatment/imaging of cancers. Chem Sci. 2018;9(4):790-810. doi: 10.1039/C7SC04004K. PubMed PMID: 29675145. PubMed PMCID: PMC5890329.

15. Zhang G, Gao J, Qian J, Zhang L, Zheng K, Zhong $\mathrm{K}$, et al. Hydroxylated mesoporous nanosilica coated by polyethylenimine coupled with gadolinium and folic acid: a tumor-targeted T1 magnetic resonance contrast agent and drug delivery system. ACS Appl Mater Interfaces. 2015;7(26):14192200. doi: 10.1021/acsami.5b04294. PubMed PMID: 26084052.

16. Shin J, Jo D, Hong SB. Rediscovery of the importance of inorganic synthesis parameters in the search for new zeolites. AAcc Chem Res. 2019;52(5):1419-1427. doi: 10.1021/acs. accounts.9b00073. PubMed PMID: 31013053.

17. Li Y, Li L, Yu J. Applications of zeolites in sustainable chemistry. Chem. 2017;3(6):928-49. doi: 10.1016/j.chempr.2017.10.009.
18. Bresinska I, Balkus KJ. Studies of Gd (III)-exchanged Y-type zeolites relevant to magnetic resonance imaging. J Phys Chem. 1994;98(49):1298994. doi: 10.1021/j100100a029.

19. Csajbók É, Bányai I, Vander Elst L, Muller RN, Zhou W, Peters JA. Gadolinium (III)-loaded nanoparticulate zeolites as potential high-field MRI contrast agents: Relationship between structure and relaxivity. Chemistry. 2005;11(16):4799-807. doi: 10.1002/chem.200500039. PubMed PMID: 15929138.

20. Mesgari-Shadi A, Sarrafzadeh MH, Divband B, Barar J, Omidi Y. Batch adsorption/desorption for purification of scfv antibodies using nanozeolite microspheres. Microporous and Mesoporous Materials. 2018;264:167-75. doi: 10.1016/j.micromeso.2018.01.028.

21. Anbia M, Aghaei M. Study of the effect of organic binders on 13X zeolite agglomeration and their $\mathrm{CO} 2$ adsorption properties. Scientia Iranica. 2019;26(3):1497-504. doi: 10.24200/ sci.2018.21198. 